\title{
Thermal and Structure Analysis Based on Exfoliation of Clay in Thermosensitive Polymer by in-situ Polymerization
}

\author{
Marwah Noori Mohammed, Kamal Bin Yusoh*, and Jun Haslinda Binti Haji Shariffuddin \\ Faculty of Chemical and Natural Resources Engineering, Universiti Malaysia Pahang, \\ Lebuhraya Tun Razak 26300, Gambang, Pahang, Malaysia
}

\begin{abstract}
${ }^{*}$ Corresponding author:
Abstract: Poly(N-vinylcaprolactam) (PNVCL) offers superior characteristics as a

tel: +60199339541

email:kamal@ump.edu.my

thermoresponsive polymer for various potential applications. An attractive procedure, namely in-situ polymerization, was used to prepare NVCL/clay nanocomposite in different clay ratios. Organo-modified clay as C20 and B30 were employed in a range

Received: August 3, 2018

Accepted: December 16, 2018

between 1-5\% based on weight. Thermogravimetric analysis (TGA) and Fourier transform infrared spectroscopy (FTIR) were used to study thermal decomposition and to

DOI: $10.22146 /$ ijc. 40872 assess bond conversion during polymerization of the nanocomposite. This research was conducted to study PNVCL characteristics with the addition of clay as a nanocomposite. The stretch mode of the carboxylic group $(C=O)$ and $(C=C)$ was present in the band range about $1635 \mathrm{~cm}^{-1}$ for the C20, but it was ranging between 1640 to $1664 \mathrm{~cm}^{-1}$ for the B30 of the nanocomposite. It was observed that the decomposition was different for each type of organoclay and the temperature peaked at 30 to $800{ }^{\circ} \mathrm{C}$, to measure the degradation points at 5, 10, and 50\%. Comparison results for FTIR and TGA showed that the best nanocomposite was found in the C20 (3\%) case.
\end{abstract}

Keywords: polymer; clay; nanocomposite; thermoresponsive; polymerization; thermal

\section{- INTRODUCTION}

In general, the term stimuli-responsive polymer can be described as the chemical or physical changes of polymer responses to a small external variation in environmental conditions [1-2]. Electric or magnetic scope, mechanical stress, and temperature are physical stimuli that critically affect and mutate molecular interactions. While the change in interaction at the molecular level between polymer chains is a chemical stimulus, which includes ionic factors, chemical agents and $\mathrm{pH}$ [3]. Research by the pharmaceutical and biological fields showed that, between all stimuliresponsive polymers, temperature responsive polymers have the most significant attention because most of the diseases that appear due to a change in temperature are vital physiological factors in the body [4-6]. Furthermore, an attractive development was also shown for various applications, such as bioseparation platforms [7], tissue engineering [8], artificial muscles [9-10], environmental issues [11] and sensors [12-13].
Poly( $N$-isopropylacrylamide) (PNIPAM) and poly( $N$-vinylcaprolactam) (PNVCL) are the most popular thermoresponsive polymers due to their lower critical solution temperature (LCST) which is about $33^{\circ} \mathrm{C}$ [14-16]. PNVCL is reported to have characteristics such as biotoxicity, biocompatibility, and solubility unlike PNIPAM [17]. The actual interest from the comparison is that PNVCL is more promising for bioanalytical and biomedical applications [18]. When utilized in medical or bio-related applications, the important factors for PNVCL are biocompatibility, macro-porosity, thermal and mechanical properties [19]. For instance, the mechanical characteristics enhancement produces PNVCL that is robust enough for scaffolds of tissue engineering and artificial cartilage [20-21] also, the macrospore structure is able to provide spaces for cell culture [22]. Therefore, it is a great technological significance when the mechanical, macroporosity and other properties of the PNVCL are developed. 
Table 1. Chemicals and materials utilized for the synthesis process

\begin{tabular}{|c|c|c|c|c|}
\hline Chemicals & Formula & Purity & Phase & Source \\
\hline Monomer & $\mathrm{C}_{8} \mathrm{H}_{13} \mathrm{NO}$ & $98 \%$ & $\mathrm{~S}$ & Aldrich \\
\hline Initiator & $\left(\mathrm{CH}_{3}\right)_{2} \mathrm{C}(\mathrm{CN}) \mathrm{N}=\mathrm{NC}\left(\mathrm{CH}_{3}\right)_{2} \mathrm{CN}$ & $98 \%$ & $\mathrm{~L}$ & Aldrich \\
\hline Hexane & $\mathrm{C}_{6} \mathrm{H}_{14}$ & $99 \%$ & $\mathrm{~L}$ & Aldrich \\
\hline Diethyl ether & $\left(\mathrm{CH}_{3} \mathrm{CH}_{2}\right)_{2} \mathrm{O}$ & $99.7 \%$ & $\mathrm{~L}$ & Aldrich \\
\hline Cloisite C20, B30 & Material & & $S$ powder & Chemical lab \\
\hline distilled water & $\mathrm{H}_{2} \mathrm{O}$ & $99 \%$ & $\mathrm{~L}$ & Chemical lab \\
\hline Ammonium hydroxide & $\mathrm{NH}_{4} \mathrm{OH}$ & & $\mathrm{L}$ & Merck \\
\hline
\end{tabular}

It is known that monomer $N$-vinyl caprolactam (NVCL) has poor solubility in aqueous solution; therefore, polymerization usually happens in alcohol/water mixed solution, and small chemical molecules are used for cross-linking [23]. In this scope, Makhaeva et al. [24] synthesized PNVCL, and it was found to have a good thermo-sensitivity and polymerization occurred via methylene bisacrylamide (BIS) as chemical cross-linker in ethyl/water mixed solution. Commonly, PNVCL is chemically cross-linked by BIS characteristic with poor mechanical properties due to variation in reactivity among the cross-linker and the monomer [25].

Imaz and Forcada, Kloxin et al. $[4,26]$ attempted to advance PNVCL mechanical properties by using other cross-linkers such as poly(ethylene glycol) diacrylate (PEGDA) and ethylene glycol dimethacrylate (EGDMA) to produce homogeneous polymeric networks. Schweikl et al. [27] also recently approved the cytotoxicity of both organic chemical cross-linkers. For physical cross-linkers, Loos et al. [28] used silica particles to prepare PNVCL by interacting with the hydrogen bonds between the PVCL carbonyl functions and silica particles in a sol-gel process. However, PNVCL preparation modality cannot stimulate macro-porosity in a polymeric matrix; therefore, silica cross-linked PNVCL nanocomposite has limited applications [29]. Substantially, the fabrication and enhancement of PNVCL properties are still challenging. As mentioned before, the drawback in the previous studies were poor mechanical properties and cytotoxicity for most of the chemical cross-linkers. Therefore, in this work, a novel thermoresponsive polymer PNVCL/clay nanocomposite was prepared by using in-situ polymerization depending on clay nanosheets safety as approved by the cytotoxicity test [30-31].

\section{- EXPERIMENTAL SECTION}

\section{Materials}

$\mathrm{N}$-vinyl caprolactam (VCL) was purchased from Sigma Aldrich with a molecular weight of $139.19 \mathrm{~g} \mathrm{~mol}^{-1}$, while, $\alpha, \alpha$-Azoisobutyronitrile, AIBN (Sigma Aldrich) was used as an initiator. Cloisite C20 and B30 bought from Sigma Aldrich and Hexane (Merck) were used as a solvent. The chemicals and materials employed for synthesis the nanocomposite are represented in Table 1.

\section{Procedure}

\section{Preparation of PNVCL/clay nanocomposite}

$\mathrm{PNVCL/clay} \mathrm{nanocomposite} \mathrm{investigated} \mathrm{in} \mathrm{this}$ study was prepared by free-radical polymerization by using clay nanosheets as cross-linking agents. Two kinds of organoclays including C20 (Cloisite ${ }^{\oplus} 20 \mathrm{~A}$, dimethyl dehydrogenated tallow quaternary ammonium (2M2HT)-MMT) and B30 (Cloisite ${ }^{\circ} 30 \mathrm{~B}$, methyl tallow bis-2-hydroxyethyl quaternary ammonium (MT2EtOH)-MMT). Before synthesis, the clay (C20 or B30) was dried overnight at $70{ }^{\circ} \mathrm{C}$ in a ventilated oven to intercalate the clay layers. A magnetic stirrer linked to a condenser was fixed, then the flask was vacuumed. A typical preparation procedure of PNVCL/clay nanocomposite gel can be described as follows: the desired amount of clay (1-5\%) was put in a $100 \mathrm{~mL}$ three-neck flask mixed with $5 \mathrm{~g}$ of NVCL and $30 \mathrm{~mL}$ of hexane at $50{ }^{\circ} \mathrm{C}$ for $1 \mathrm{~h}$. To start polymerization, the solution was heated at $60{ }^{\circ} \mathrm{C}$ then $1 \mathrm{~mL}$ of AIBN was dissolved in a $10 \mathrm{~mL}$ of hexane and injected into the 
solution by using a syringe. After a wash with methanol and water (1:1) to remove the unreacted chemicals, the PNVCL/clay nanocomposite was dried in the vacuum oven to obtain a yellowish gel.

\section{Characterization}

To identify the bonding structure between the clay particles (C20 and B30) and monomer in the in-situ polymerization, FTIR spectrometer was utilized [32]. Nicolet (Avatar 370 DTGS) was used with a resolution of $4 \mathrm{~cm}^{-1}$ from 4000 to $400 \mathrm{~cm}^{-1}$. To increase the signal to noise ratio, each spectrum was taken as an average of 64 scans. TGA measures the amount and rate of change in the weight of a material as a function of temperature or time $[5,21,33]$. The technique can characterize materials that exhibit weight loss or gain due to decomposition, oxidation or dehydration. Samples curves were plotted with the mass change expressed in percent versus temperature or time. Each sample weighted $10 \mathrm{mg}$ and was heated from 30 to $800^{\circ} \mathrm{C}$ at $5^{\circ} \mathrm{C} / \mathrm{min}$ under nitrogen.

\section{- RESULTS AND DISCUSSION}

PNVCL/clay nanocomposite and NVCL were analyzed by using FTIR to detect if polymerization had occurred. From the NVCL monomer spectrum, amide group $(\mathrm{C}=\mathrm{O})$ at $1624 \mathrm{~cm}^{-1}$ was detected and $\mathrm{C}-\mathrm{C}$ observed at $1430 \mathrm{~cm}^{-1}$ was presented to the aliphatic group in the caprolactam ring. Moreover, a further characteristic of $\mathrm{C}=\mathrm{C}$ peak appeared at $1648 \mathrm{~cm}^{-1}$ and $\mathrm{C}-\mathrm{H}$ stretching

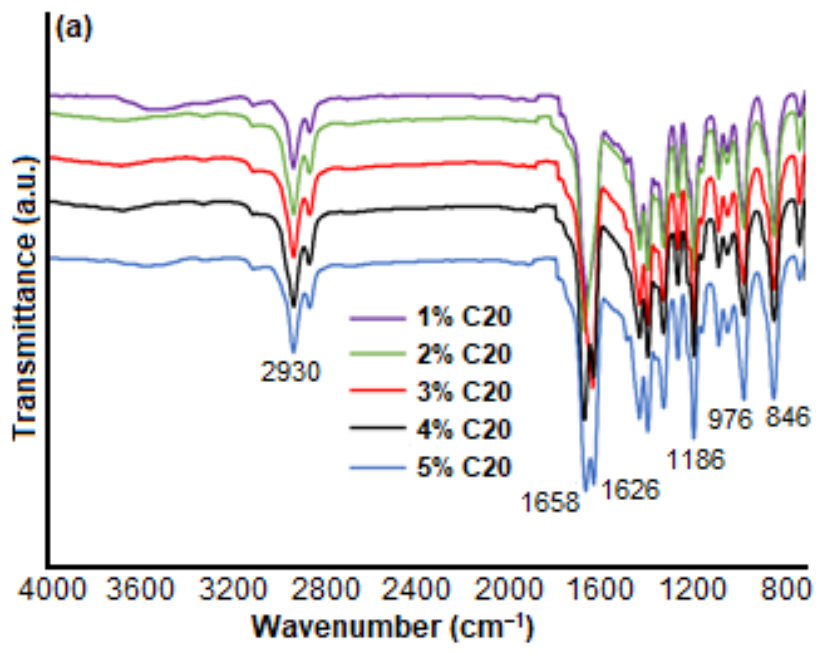

band was observed at $3108 \mathrm{~cm}^{-1}$ in correspondence with studies by Lee et al. and Halligan et al. [8,34].

To ensure polymerization was achieved, i.e., $\mathrm{C}-\mathrm{H}$ and $\mathrm{C}=\mathrm{C}$ bands disappeared in the vinyl group of the NVCL monomer; NVCL/C20 (3\%) case was investigated. Fig. 1(a) exhibits the NVCL/C20 spectra new peaks that were not typically associated with PNVCL from the literature as the clay was affected. The $\mathrm{C}-\mathrm{H}$ stretch bond peaks in the range of $2852-2936 \mathrm{~cm}^{-1}$ corresponded to hydroxyl $(\mathrm{C}-\mathrm{H})$ group present on the composite surface [35]. The band, centered at $\sim 1635 \mathrm{~cm}^{-1}$, represents the stretch mode of the carboxylic group $(\mathrm{C}=\mathrm{O})$ [36]. The presence of the above-mentioned carbonyl group indicates that organoclays are chemically linked to the polymer through hydrogen bonding, thereby, forming the polymer/clay nanocomposite. The interaction increases with the increase in the ratio of $\mathrm{C} 20$ in NVCL, thus, confirming NVCL/C20 polymerization within the organically modified galleries of Cloisite C20 (Fig. 1(b)).

The vibrations related to hydrogen bonding were observed at a range of $1542-1686 \mathrm{~cm}^{-1}$, found more intense with the increasing percentage of organoclay in the nanocomposites matrix (PNVCL - C20), as compared to neat PNVCL [37]. Furthermore, nanoclay (Cloisite $\mathrm{C} 20$ ) has $\mathrm{OH}$ groups on its surface and according to the hypothesis of Ross et al. they might interact with -NCO groups of the isocyanate [38].

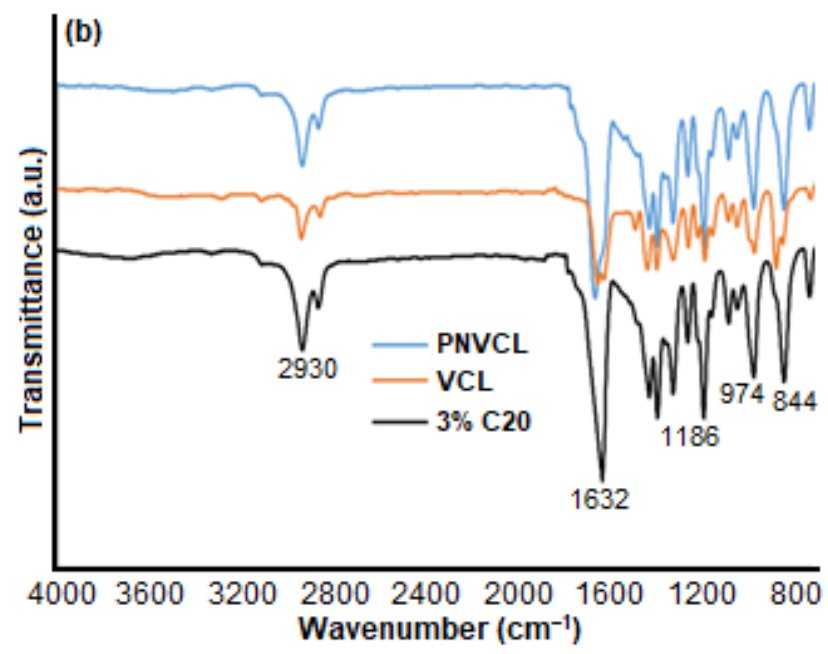

Fig 1. FTIR spectra of: (a) NVCL/C20 (1-5\%), (b) PNVCL, NVCL, and NVCL/C20 (3\%) 

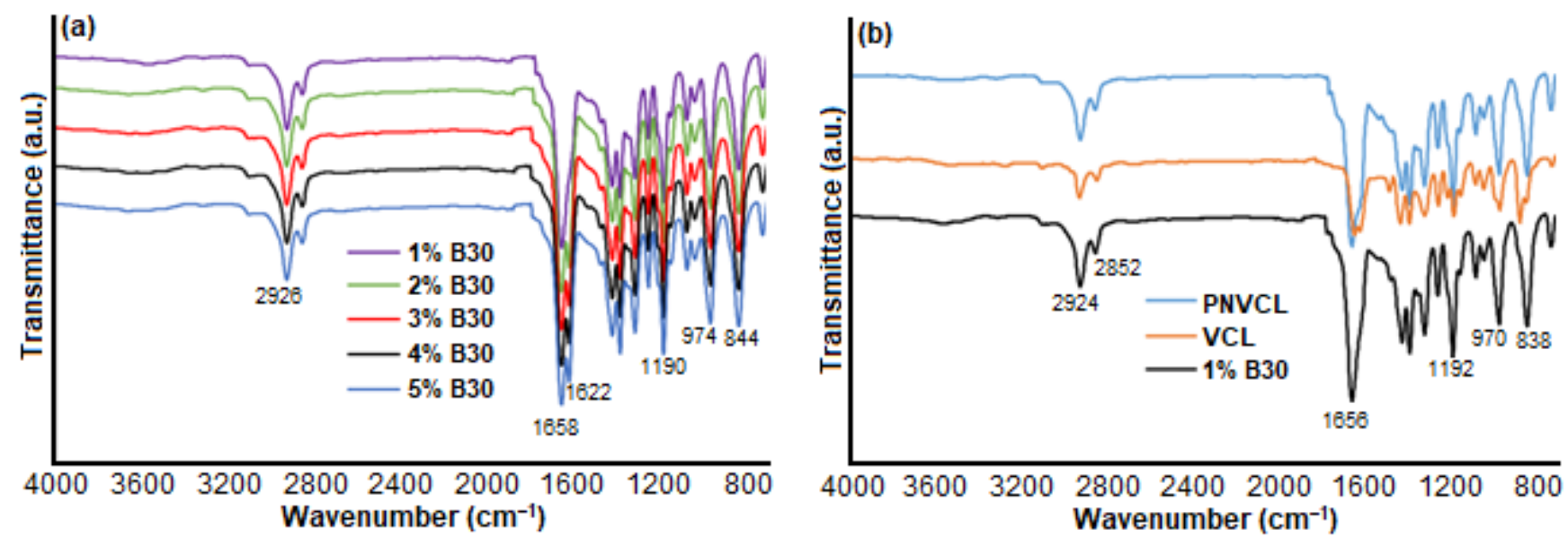

Fig 2. FTIR spectra of: (a) NVCL/B30 (1-5\%), (b) PNVCL, VCL, and NVCL/B30 (1\%)

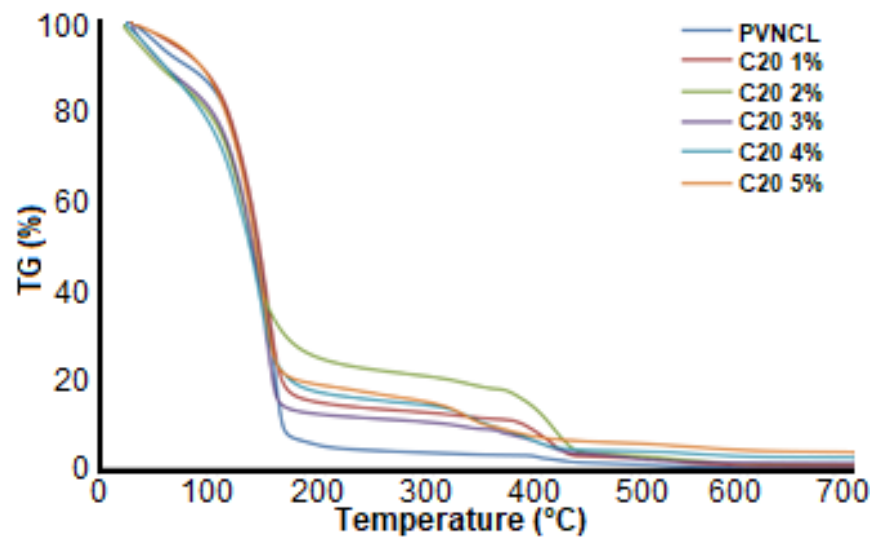

Fig 3. TGA derivative curves for PNVCL and NVCL/C20 (1-5\%) nanocomposite

B30 effect on the nanocomposite surface based on the FTIR measurements in five ratios are shown in Fig. 2(a). It is clear that the $\mathrm{B} 30$ is present in the nanocomposite produced in this study. The $\mathrm{C}-\mathrm{H}$ stretch band peaks in the range of $2832-2942 \mathrm{~cm}^{-1}$ corresponded to hydroxyl $(\mathrm{C}-\mathrm{H})$ group present on the composite surface. The stretch mode of the carboxylic group $(\mathrm{C}=\mathrm{O})$ and $(\mathrm{C}=\mathrm{C})$ was present in the band range between 1640 to $1664 \mathrm{~cm}^{-1}$ [39]. Fig. 2(b) shows the $\mathrm{C}=\mathrm{O}$ peak shifting from $1640 \mathrm{~cm}^{-1}$ of NVCL to $1656 \mathrm{~cm}^{-1}$ of NVCL/B30, representing clay intercalation in the nanocomposite. The vibration bands observed for different PNVCL-clays ratios at about wavenumber 1000 to $1100 \mathrm{~cm}^{-1}$ as shown in Fig. 2(a) were due to Si-O stretching and this results corresponding with the study by Sarkar et al. [40].

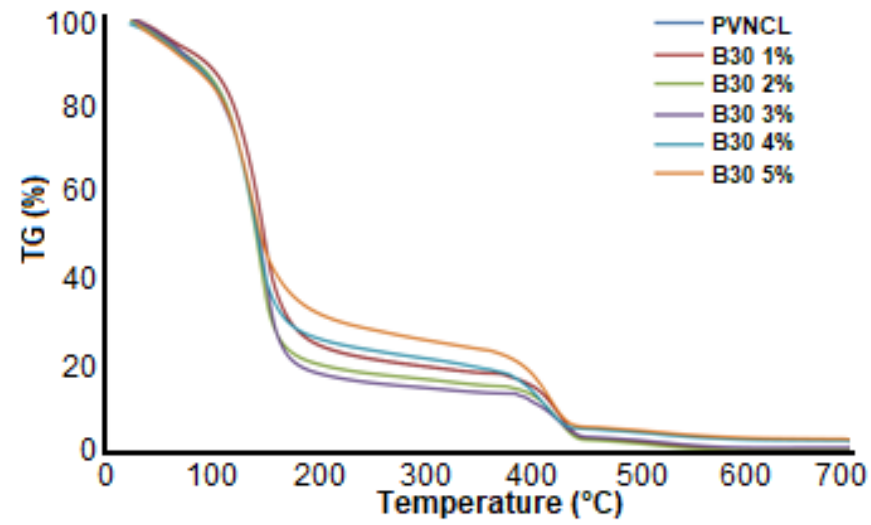

Fig 4. TGA derivative curves for PNVCL and NVCL/B30(1-5\%) nanocomposite

Results of the TGA weight loss profile of the polymer/clay nanocomposite dried powder samples are shown in Fig. 3 and 4. Organo-modified C20 and B30 were used in this study as a clay. Weight loss occurred when the sample was heated from 30 to $800{ }^{\circ} \mathrm{C}$. The curves in the figures designate the percentage of weight loss with the effect of temperature increase. It can be observed that the weight loss behavior for all samples was huge. Three regions were selected in the TGA pattern for all samples in Fig. 3 and 4. In the first region, the degradation of the mass was very sharp at the temperature range between 100 to $170{ }^{\circ} \mathrm{C}$ as shown in Fig. 3 but in Fig. 4 was ranging from 90 to $150{ }^{\circ} \mathrm{C}$. This is due to the loss of the weakly bound $\mathrm{OH}$ group and physically adsorbed water from the samples [41]. 
Table 2. TGA data for PNVCL and nanocomposites under nitrogen flow

\begin{tabular}{lccccc}
\hline \multirow{2}{*}{ Sample } & \multicolumn{3}{c}{ Temperature $/{ }^{\circ} \mathrm{C}$ at mass loss } & \multicolumn{2}{c}{ Residue \% at } \\
\cline { 2 - 6 } & $5 \%$ & $10 \%$ & $50 \%$ & $500{ }^{\circ} \mathrm{C}$ & $600{ }^{\circ} \mathrm{C}$ \\
\hline PNVCL & 53.24 & 81.01 & 147.14 & 1.16 & 0.43 \\
NVCL + 1\% (C20) & 66.95 & 93.87 & 147.80 & 2.37 & 0.90 \\
NVCL + 2\% (C20) & 37.54 & 56.84 & 141.88 & 3.06 & 1.47 \\
NVCL + 3\% (C20) & 42.93 & 61.88 & 141.94 & 2.44 & 1.60 \\
NVCL + 4\% (C20) & 42.01 & 60.54 & 139.08 & 4.09 & 2.96 \\
NVCL + 5\% (C20) & 71.18 & 94.21 & 144.72 & 5.84 & 4.31 \\
NVCL + 1\% (B30) & 60.38 & 92.52 & 148.66 & 2.62 & 0.62 \\
NVCL + 2\% (B30) & 58.06 & 86.58 & 141.57 & 2.17 & 0.58 \\
NVCL + 3\% (B30) & 59.49 & 82.83 & 143.97 & 2.95 & 1.24 \\
NVCL + 4\% (B30) & 59.05 & 86.08 & 143.19 & 4.77 & 3.11 \\
NVCL + 5\% (B30) & 56.93 & 82.40 & 146.16 & 5.28 & 3.56 \\
\hline
\end{tabular}

Meanwhile, the degradation of the total weight of the samples ranged from 60 to $95 \%$ as shown in Fig. 3, as well as the degradation, was ranging from 56 to $80 \%$ as shown in Fig. 4. This behavior appeared in all clay types (C20 and $\mathrm{B} 30)$. In the second region, the gradual change of weight at a temperature between 170 to $450{ }^{\circ} \mathrm{C}$ for $\mathrm{C} 20$ and 156 to $400{ }^{\circ} \mathrm{C}$ for $\mathrm{B} 30$ corresponded to the removal of organic clay residues, interlayer anions and further polymerization of the monomer network [42-43]. The third region showed the lowest weight loss at a temperature above $500{ }^{\circ} \mathrm{C}$ due to the strongly bound interlayer anions and removal of the $\mathrm{OH}$ group from the sample for both clay types (C20 and B30) as shown in Fig. 3 and 4 . The thermograms in Fig. 3 and 4 show that, after an initial loss of $20 \%$ of the original weight, there is an almost total rapid degradation of the pure PVNCL and the nanocomposites in the range from 170 to $450{ }^{\circ} \mathrm{C}$. For the decomposition of the nanocomposites around $15-30 \%$ is left, probably corresponding to the remaining clay and polymer ashes [42].

Comparison of weight loss through TGA for all nanocomposite samples obtained from polymer/clay polymerization is shown in Table 2 . Temperature at weight loss 10 and $50 \%$, and residue at 500 and $600{ }^{\circ} \mathrm{C}$ are also presented in Table 2 . It can be clearly observed that the percentage of residue increases with the increase in clay ratio from 1 to $5 \%$ in the nanocomposite. When the temperature increased to $600^{\circ} \mathrm{C}$, the polymer residue was $0.425 \%$. On the other hand, when C20 clay was used, the nanocomposite residue ranged from 0.9 to $4.31 \%$ based on the increase in clay ratio. The nanocomposite residue increased from 0.618 to $3.560 \%$ with the increase of B30 ratio at a temperature of $600{ }^{\circ} \mathrm{C}$. This is ascribed to the continued elimination of strongly bound anions and a small contribution of the $\mathrm{OH}$ group.

\section{- CONCLUSION}

In summary, a novel biocompatible thermoresponsive PNVCL-Clay nanocomposite was fabricated, and the successful polymerization conformed to the data via FTIR and TGA. This study allows a much greater understanding of the $\mathrm{C} 20$ and B30 intercalation based on the polymer systems that were influenced by the weight ratio. On the basis of the FTIR spectrometer; the shifting of the PNVCL/C20 characteristics and $\mathrm{PNVCL} / \mathrm{B} 30$ peaks, it can be concluded that the C20 layers intercalation had taken place at NVCL interior more than that of B30. FTIR results confirmed the inclusion of clay in the polymer matrix. Mainly, intercalated composites were obtained. Furthermore, when C20 was used, the NVCL/C20 nanocomposite residue ranged from 0.9 to $4.31 \%$ based on the increase in clay ratio per weight. Besides that, the NVCL/B30 residue at a temperature of $600{ }^{\circ} \mathrm{C}$ also increased from 0.62 to $3.56 \%$ with the increase in ratio. The nanocomposites exhibited improvement in thermal stability as determined by TGA, mainly due to its intercalated structure. TGA data showed that the with 
higher clay loadings the depolymerization stage becomes less important, suggesting that the clay affects the mechanism of thermal degradation.

\section{- ACKNOWLEDGMENTS}

The authors would like to be obliged to Universiti Malaysia Pahang for providing laboratory facilities and financial assistance under FRGS research grant (RDU160149) and the internal research funding (RDU150398).

\section{- REFERENCES}

[1] Strachota, B., Matějka, L., Zhigunov, A., Konefał, R., Spěváček, J., Dybal, J., and Puffr, R., 2015, Poly(Nisopropylacrylamide)-clay based hydrogels controlled by the initiating conditions: evolution of structure and gel formation, Soft Matter, 11 (48), 9291-9306.

[2] Francis, R., Gopalan, G.P., Sivadas, A., and Joy, N., 2016, "Properties of Stimuli-Responsive Polymers" in Biomedical Applications of Polymeric Materials and Composites, Eds. Francis, R., and Kumar, D.S., Wiley-VCH Verlag GmbH \& Co. KGaA, Kottayam, Kerala, India, 187-231.

[3] Karakasyan, C., Mathos, J., Lack, S., Davy, J., Marquis, M., and Renard, D., 2015, Microfluidicsassisted generation of stimuli-responsive hydrogels based on alginates incorporated with thermoresponsive and amphiphilic polymers as novel biomaterials, Colloids Surf., B, 135, 619-629.

[4] Imaz, A., and Forcada, J., 2010, $N$-vinylcaprolactambased microgels for biomedical applications, $J$. Polym. Sci., Part A: Polym. Chem., 48 (5), 1173-1181.

[5] Mohammed, M.N., Yusoh, K.B., and Shariffuddin, J.H.B.H., 2018, Poly( $N$-vinyl caprolactam) thermoresponsive polymer in novel drug delivery systems: A review, Mater. Express, 8 (1), 21-34.

[6] Wu, W., and Zhou, S., 2013, "Responsive PolymerInorganic Hybrid Nanogels for Optical Sensing, Imaging, and Drug Delivery" in Nanomaterials in Drug Delivery, Imaging, and Tissue Engineering, Eds. Tiwari, A., and Tiwari, A., Willey, Hoboken, New Jersey, 263-314.
[7] Nagase, K., Kobayashi, J., and Okano, T., 2009, Temperature-responsive intelligent interfaces for biomolecular separation and cell sheet engineering, J. R. Soc. Interface, 6 (Suppl 3), S293-S309.

[8] Lee, B., Jiao, A., Yu, S., You, J.B., Kim, D.H., and Im, S.G., 2013, Initiated chemical vapor deposition of thermoresponsive poly $(N$-vinylcaprolactam $)$ thin films for cell sheet engineering, Acta Biomater., 9 (8), 7691-7698.

[9] Seliktar, D., 2012, Designing cell-compatible hydrogels for biomedical applications, Science, 336 (6085), 1124-1128.

[10] Malhotra, A., Mcinnis, M., Anderson, J., and Zhai, L., 2013, "Stimuli-Responsive Conjugated Polymers: From Electronic Noses to Artificial Muscles" in Intelligent Stimuli-Responsive Materials, Eds. Li, Q., Wiley, Hoboken, New Jersey, 423-470.

[11] Sanna, R., Fortunati, E., Alzari, V., Nuvoli, D., Terenzi, A., Casula, M.F., Kenny, J.M., and Mariani, A., 2013, Poly( $N$-vinylcaprolactam) nanocomposites containing nanocrystalline cellulose: A green approach to thermoresponsive hydrogels, Cellulose, 20 (5), 2393-2402.

[12] Sorber, J., Steiner, G., Schulz, V., Guenther, M., Gerlach, G., Salzer, R., and Arndt, K.F., 2008, Hydrogel-based piezoresistive $\mathrm{pH}$ sensors: Investigations using FT-IR attenuated total reflection spectroscopic imaging, Anal. Chem., 80 (8), 2957-2962.

[13] Granados-Focil, S., 2015, "Stimuli-Responsive Polymers as Active Layers for Sensors" in Functional Polymer Coatings: Principles, Methods, and Applications, Eds. Wu, L., and Baghdachi, J., John Wiley \& Sons, Inc., Hoboken, New Jersey, 163-196.

[14] Lau, A.C.W., and Wu, C., 1999, Thermally sensitive and biocompatible poly( $N$-vinylcaprolactam): Synthesis and characterization of high molar mass linear chains, Macromolecules, 32 (3), 581-584.

[15] Maeda, Y., Nakamura, T., and Ikeda, I., 2002, Hydration and phase behavior of $\operatorname{poly}(N-$ 
vinylcaprolactam $)$ and poly( $N$-vinylpyrrolidone) in water, Macromolecules, 35 (1), 217-222.

[16] Beija, M., Marty, J.D., and Destarac, M., 2011, Thermoresponsive poly( $N$-vinyl caprolactam)coated gold nanoparticles: Sharp reversible response and easy tenability, Chem. Commun., 47 (10), 28262828.

[17] Cortez-Lemus, N.A., and Licea-Claverie, A., 2016, Poly(N-vinylcaprolactam), a comprehensive review on a thermoresponsive polymer becoming popular, Prog. Polym. Sci., 53, 1-51.

[18] Liu, J., Debuigne, A., Detrembleur, C., and Jérôme, C., 2014, Poly( $N$-vinylcaprolactam): A thermoresponsive macromolecule with promising future in biomedical field, Adv. Healthcare Mater., 3 (12), 1941-1968.

[19] Imran, A.B., Esaki, K., Gotoh, H., Seki, T., Ito, K., Sakai, Y., and Takeoka, Y., 2014, Extremely stretchable thermosensitive hydrogels by introducing slide-ring polyrotaxane cross-linkers and ionic groups into the polymer network, Nat. Commun., 5, 1-8.

[20] Sun, J.Y., Zhao, X., Illeperuma, W.R., Chaudhuri, O., Oh, K.H., Mooney, D.J., Vlassak, J.J., and Suo, Z., 2012, Highly stretchable and tough hydrogels, Nature, 489 (7414), 133-136.

[21] Mohammed, M.N., Yusoh, K.B., and Shariffuddin, J.H.B.H., 2016, Methodized depiction of design of experiment for parameters optimization in synthesis of $\operatorname{poly}(N$-vinylcaprolactam $)$ thermoresponsive polymers, Mater. Res. Express, 3 (12), 125302.

[22] Murphy, C.M., Haugh, M.G., and O'Brien, F.J., 2010, The effect of mean pore size on cell attachment, proliferation and migration in collagenglycosaminoglycan scaffolds for bone tissue engineering, Biomaterials, 31 (3), 461-466.

[23] Rao, K.M., Rao, K.S.V.K., and Ha, C.S., 2016, Stimuli responsive poly(vinyl caprolactam) gels for biomedical applications, Gels, 2 (1), 6.

[24] Makhaeva, E.E., Thanh, L.T.M., Starodoubtsev, S.G., and Khokhlov, A.R., 1996, Thermoshrinking behavior of poly(vinylcaprolactam) gels in aqueous solution, Macromol. Chem. Phys., 197 (6), 1973-1982.
[25] Belyaev, A.K., Irschik, H., and Krommer, M., 2016, Mechanics and Model-based Control of Advanced Engineering Systems, Springer-Verlag Wien, New Delhi, India, 76.

[26] Kloxin, A.M., Kloxin, C.J., Bowman, C.N., and Anseth, K.S., 2010, Mechanical properties of cellularly responsive hydrogels and their experimental determination, Adv. Mater., 22 (31), 3484-3494.

[27] Schweikl, H., Hiller, K.A., Bolay, C., Kreissl, M., Kreismann, W., Nusser, A., Steinhauser, S., Wieczorek, J., Vasold, R., and Schmalz, G., 2005, Cytotoxic and mutagenic effects of dental composite materials, Biomaterials, 26 (14), 1713-1719.

[28] Loos, W., Verbrugghe, S., Goethals, E.J., Du Prez, F.E., Bakeeva, I.V., and Zubov, V.P., 2003, Thermoresponsive organic/inorganic hybrid hydrogels based on poly(N-vinylcaprolactam), Macromol. Chem. Phys., 204 (1), 98-103.

[29] Gomes, M.E., Holtorf, H.L., Reis, R.L., and Mikos, A.G., 2006, Influence of the porosity of starch-based fiber mesh scaffolds on the proliferation and osteogenic differentiation of bone marrow stromal cells cultured in a flow perfusion bioreactor, Tissue Eng., 12 (4), 801-809.

[30] Gürses, A., 2015, Introduction to Polymer-Clay Nanocomposites, CRC Press, Taylor \& Francis Group, U.S, 105.

[31] Alcântara, A.C.S., Darder, M., Aranda, P., Ayral, A., and Ruiz-Hitzky, E., 2016, Bionanocomposites based on polysaccharides and fibrous clays for packaging applications, J. Appl. Polym. Sci., 133 (2), 42362.

[32] Zhang, T., Yuan, Y., Cui, X., Yin, H., Gu, J., Huang, H., and Shu, J., 2018, Impact of side-chain length on the phase structures of P3ATs and P3AT: PCBM films as revealed by SSNMR and FTIR, J. Polym. Sci., Part B: Polym. Phys., 56 (9), 751-761.

[33] Lyon, R.E., Safronava, N., and Crowley, S., 2018, Thermal analysis of polymer ignition, Fire Mater., 42 (6), 668-679.

[34] Halligan, S.C., Dalton, M.B., Murray, K.A., Dong, Y., Wang, W., Lyons, J.G., and Geever, L.M., 2017, 
Synthesis, characterisation and phase transition behaviour of temperature-responsive physically crosslinked poly ( $N$-vinylcaprolactam) based polymers for biomedical applications, Mater. Sci. Eng., C, 79, 130-139.

[35] Dimitriou, A., Hale, M.D., and Spear, M.J., 2018, The effect of $\mathrm{pH}$ on surface activation of wood polymer composites (WPCs) with hydrogen peroxide for improved adhesion, Int. J. Adhes. Adhes., 85, 44-57.

[36] Subramani, S., Choi, S.W., Lee, J.Y., and Kim, J.H., 2007, Aqueous dispersion of novel silylated (polyurethane-acrylic hybrid/clay) nanocomposite, Polymer, 48 (16), 4691-4703.

[37] Zhang, J., Wu, Q., Li, M.C., Song, K., Sun, X., Lee, S.Y., and Lei, T., 2017, Thermoresponsive copolymer poly( $N$-vinylcaprolactam $)$ grafted cellulose nanocrystals: Synthesis, structure, and properties, ACS Sustainable Chem., 5 (8), 7439-7447.

[38] Ross, P., Escobar, G., Sevilla, G., and Quagliano, J., 2017, Micro and nanocomposites of polybutadienebased polyurethane liners with mineral fillers and nanoclay: Thermal and mechanical properties, Open Chem., 15 (1), 46-52.
[39] Kalaivasan, N., and Syed Shafi, S., 2017, Enhancement of corrosion protection effect in mechanochemically synthesized Polyaniline/MMT clay nanocomposites, Arabian J. Chem., 10 (Suppl. 1), S127-S133.

[40] Sarkar, S., Datta, S.C., and Biswas, D.R., 2014, Synthesis and characterization of nanoclaypolymer composites from soil clay with respect to their water-holding capacities and nutrient-release behaviour, J. Appl. Polym. Sci., 131 (6), 39951.

[41] Gun'ko, V.M., Savina, I.N., and Mikhalovsky, S.V., 2017, Properties of water bound in hydrogels, Gels, 3 (4), 37.

[42] Fecchio, B.D., Valandro, S.R., Neumann, M.G., and Cavalheiro, C., 2016, Thermal decomposition of polymer/montmorillonite nanocomposites synthesized in situ on a clay surface, J. Braz. Chem. Soc., 27 (2), 278-284.

[43] Shahabadi, S.I.S., and Garmabi, H., 2014, Qualitative assessment of nanoclay dispersion using thermogravimetric analysis: A response surface study, J. Thermoplast. Compos. Mater., 27 (4), 498517. 